\title{
RVOT Septal Pacing: Short Review of History and Technical Requirements for Successful Implantation
}

\author{
Sudeb Mukherjee* \\ Institute of Cardiovascular Science, India
}

Submission: June 08, 2018; Published: August 15, 2018

*Corresponding author: Sudeb Mukherjee, Post Doctorate Fellow, Institute of Cardiovascular Science, Institute of Post Graduate Medical Education and Research, Kolkata, India, Email: drsumukherjee@gmail.com

\begin{abstract}
The idea of Right Ventricular Outflow Tract (RVOT) septal pacing is based on the fact that the septal region of the RVOT and mid RV are the first zones of the ventricle to depolarise, suggesting that pacing from these areas on the right side of the septum would achieve as normal a contraction pattern as possible. This mini review describes short history of pacemaker and evolution of concept of physiological pacing like RVOT Pacing and its technical aspects of successful implantation.
\end{abstract}

Keywords: Right ventricular outflow tract; Physiological pacing

Abbreviation: RVOT: Right Ventricular Outflow Tract; RV: Right Ventricular; CTOPP: Canadian Trial of Physiological Pacing

\section{A Short History of Pacing}

Since the era of Hippocrates (460-375BC) physicians were aware of syncope. Innovative works by different scientists at different times enriched the history of pacemakers gradually. In late 1800's McWilliam [1] laid down the basic concepts of modern pacing in detail. The first external cardiac pacemaker has been developed by Lidwell [2]. In Hyman's device, the DC current generator was directed into patient's right atrium through a bipolar needle electrode introduced via intercostals space. Zoll [3] modernized the concept of pacing radically. He had developed the external tabletop pacemaker that was successfully applied to the treatment of heart block. The electro dyne PM -65 pacemaker designed by Zoll [3] consists of an electrocardiograph to monitor the cardiac rhythm and an electric pulse generator to pace the heart. Earl E. Bakken, electrical engineer, TV repairman and cofounder of Medtronic Inc. produced the first battery-operated wearable pacemaker later that year. Bakken's pacemaker is one of the first successful applications of transistor technology to medical devices helping to launch the new field of "medical electronics. The first myocardial wire was implanted on $30^{\text {th }}$ January 1957 in a 3 year old girl in whom heart block had complicated repair of tetralogy.

On October $8^{\text {th }}, 1958$ the first pacemaker implantation was performed in Sweden. The system has been developed by the surgeon Ake Senning and the physician inventor Rune Elmqvist and implanted on a 43year old engineer called Arne Larsson. It wasn't until late 1959, when Dr. William Chardack and Dr. Andrew Gage at the Veterans Administration Hospital in Buffalo, N.Y., working with electrical engineer William Great batch, came up with a viable implantable pacemaker using primary cells as a power source. It was known as the Chardack-Great batch implantable pacemaker. Microprocessor-driven pacemakers appeared in around 1990. These became very complex devices capable of detecting and storing events utilising several algorithms. The rate-response pattern also adjusted itself automatically to the patient's activity level [1-4].

\section{Evolution of RVOT Pacing-Physiological Pacing}

From the first human implantation the Right Ventricular (RV) apical pacing has saved millions of lives, but within one decade it was proved to be non-physiological as causes several deleterious hemodynamic effects. Right ventricular apical pacing alters left ventricular electrical and mechanical activation. Chronic right ventricular apical pacing causes left ventricular dilatation and reduction of left ventricular ejection fraction. During RV apical pacing, the conduction of the electrical wave front propagates through the myocardium, rather than through the His-Purkinje conduction system. As a result the electrical wave form propagates more slowly and induces heterogeneity in electrical activation of myocardium comparable to left bundle branch block. The term physiological was first used in the Canadian Trial of Physiological Pacing (CTOPP) to reflect the terminology at the time of development of the trial. However, despite maintenance of atrio-ventricular synchrony the dual chamber pacemakers 
(DDD/R) in the different randomised controlled trials have failed to show its superiority over single chamber RV apical pacing in term of death, progression of heart failure and atrial fibrillation [5]. With the advances in the active endocardial lead system, different alternative right ventricular pacing sites such as Right ventricular outflow tract, RV septum and His and para-His bundle have been explored to replace the RV apex.

The idea of septal pacing is based on the fact that the septal region of the RVOT and mid RV are the first zones of the ventricle to depolarise, suggesting that pacing from these areas on the right side of the septum would achieve as normal a contraction pattern as possible.

\section{Technical Details of Successful RVOT Septal Pacing}

First step is to achieve the venous access to subclavian vein either by cephalic cut down or by direct puncture (preferably extrathoracic than intrathoracic) in either side(preferably in left side because of natural curve from the left. 2 nd step is to position the lead onto septum in outflow tract or mid cavity. The main challenge in septal position is to shape a stylet that consistently places the lead on the RV septum, whether this is RVOT or mid RV. Innovative works by professor Mond et al. [4] resulted in development of Mond's stylet. First a generous curve is created in distal 5 to $6 \mathrm{~cm}$ of the stylet wire. Then the terminal $2 \mathrm{~cm}$ is bent to create a swan neck deformity. However, to reliably position the lead in RV septum, a posterior-angulations is essential. Such a shaped lead is now commercially available.

After obtaining venous access, the lead tip is advanced into the pulmonary artery through the right atrium and right ventricle. The lead should be at least $58 \mathrm{~cm}$ in length, particularly when implanted from the left side. Any commercially available 6 or 7 French lead can be used. Prior to lead insertion, the septal stylet should be loaded into the lead. Some operators prefer to use slightly curved handmade stylet to position the lead in pulmonary artery or RVOT then exchange with septal stylet. This method is helpful particularly in patients with tricuspid regurgitation with dilated right sided chambers. Once the lead tip is in the pulmonary artery or RV outflow tract, the lead is gradually prolapsed into the septum and contact is made with the septal wall. This is best achieved by using PA projection. This can be confirmed by gently pushing the lead a bit so that the lead tip is seen to arch against the wall. In very large RV chamber, it is not surprising that contact may not be easy. In this situation, wider stylet may be used. Once the lead tip makes contact with the septum, the screw should be immediately deployed. The standard technique is to use inverted V clipon tool. Once the screw is deployed the stylet is gently withdrawn to right atrium to confirm wall attachment. The 40 degree LAO projection should now be performed to confirm septal positioning.

Last step in lead testing about 5 minutes following screw deployment to allow the stimulation threshold to fall and plateau following initial trauma to the endomyocardium. First to check the
$\mathrm{R}$ wave size and the stimulation threshold. A posteriorly facing lead in LAO view suggests septal location and left lateral view confirms the position of the septum.

\section{Discussion}

Permanently implantable pacing leads evolved from the temporary pacing wires that were first used to provide bradycardia support. The initial permanent transvenous leads were unipolar and consisted of a basic conductor an insulator and a connector pin. The development of a bipolar pacing leads minimised the far field oversensing. Bipolar leads consist of two longitudinal conductors separated only by a thin layer of insulation. The development of a passive fixation tines was a huge step forward. Passive fixation leads reduced the rate of reoperation because of lead dislodgement. Active fixation helices were introduced subsequently and further improved the stability of implanted leads. Chronic threshold rise and late exit block were still major problems in cardiac pacing at this stage until the revolutionary incorporation of dexamethas one elution at the porous tip of the reservoir electrode. Subsequent advances have included the universal standardisation of connector pins and consequently device headers, improving lead longevity through the use of better component materials and improving sensing through the use of narrower bipoles.

Mond et al. [5] suggested left lateral view as specific view (100\%) for confirmation of the septal position of the RV lead. However achieving routine left lateral view during pacing for sterility reason. But, 40 degree LAO view can be easily performed during lead implantation. Forty degree has been chosen as it is near maximum orientation in the oblique position that can be without compromising the sterility. Several other studies have tried to confirm true septal pacing by incorporating CT scan later on. But this is not feasible intra operatively and also radiation exposure is high. Echocardiographic support intra operatively has not been successful in several other studies. Therefore time of need is to make new technical improvements so that a physiological pacing like RVOT septal pacing becomes technically less challenging.

\section{References}

1. McWilliam JA (1889) Electrical stimulation of the heart in man. Br Med J 1(1468): 348-350.

2. Lidwill MC (1929) Cardiac disease and anaesthesia, Austral Asian medical congress (British medical association). Australia Med J Austral 2: 574-575.

3. Zoll PM (1952) Resuscitation of the heart in ventricular standstill by external electric stimulation. N Engl J Med 247(20): 768-771.

4. Mond H, Sloman J, Edwards R (1982) The first pacemaker pacing and clinical electrophysiology. Pace 5(2): 278-282.

5. Mond HG, Hillock RJ, Stevenson IH, McGavigan AD (2007) The right ventricular outflow tract: the road to septal pacing. Pacing Clin Electrophysiol 30(4): 482-491. 
Your next submission with Juniper Publishers will reach you the below assets

- Quality Editorial service

- Swift Peer Review

- Reprints availability

- E-prints Service

- Manuscript Podcast for convenient understanding

- Global attainment for your research

- Manuscript accessibility in different formats

( Pdf, E-pub, Full Text, Audio)

- Unceasing customer service

Track the below URL for one-step submission https://juniperpublishers.com/online-submission.php 